\title{
Energetic ion dynamics of the inner magnetosphere revealed in coordinated Cluster-Double Star observations
}

\author{
Iannis Dandouras, ${ }^{1,2}$ Jinbin Cao, ${ }^{3}$ and Claire Vallat ${ }^{4}$ \\ Received 24 August 2007; revised 11 September 2008; accepted 5 November 2008; published 27 January 2009.
}

[1] Since early 2004 the Chinese spacecraft Tan Ce 1 (TC-1), first component of the

Double Star (DSP) mission, has been on an equatorial elliptical orbit (13.4 $R_{E}$ apogee), allowing the study of the dynamics of the Earth's magnetosphere in conjunction with the four European Cluster spacecraft (19.6 $R_{E}$ apogee). The Cluster and Double Star spacecraft orbits are such that the spacecraft are almost in the same meridian, allowing conjugate studies. The four Cluster spacecraft highly eccentric polar orbit at $4 R_{E}$ perigee permits them to sample the ring current, the radiation belts, and the outer plasmasphere from south to north, almost following the same magnetic flux tube (latitudinal profile), whereas TC-1, with its very low-perigee equatorial orbit, gives the plasma profile across $L$ shells. Coordinated ion measurements provided by the Cluster Ion Spectrometry and Hot Ion Analyzer instruments onboard Cluster and TC-1, respectively, obtained during quiet conditions, disturbed geomagnetic conditions, and an intense storm, are used to analyze crossings of the plasmasphere and the ring current region. Multiple narrow ion energy bands ("nose-like" structures) are simultaneously observed by both Cluster and TC-1. These observations reveal the large-scale character of these structures and pose a challenge for the simulation and modeling of the inner magnetosphere populations.

Citation: Dandouras, I., J. Cao, and C. Vallat (2009), Energetic ion dynamics of the inner magnetosphere revealed in coordinated Cluster-Double Star observations, J. Geophys. Res., 114, A01S90, doi:10.1029/2007JA012757.

\section{Introduction}

[2] The ring current in the Earth's magnetosphere is toroidal shaped and flows in the near-Earth region, where the magnetic field is dipole-like. This current system is driven by the pressure gradients, and it is formed by the drift of charged energetic particles $(\sim 1 \mathrm{keV}$ to a few hundred of $\mathrm{keV})$ trapped in the geomagnetic field [e.g., Daglis et al., 1999]. These particles are injected from the magnetotail toward the Earth during magnetospheric storms and substorms, or are convected from the magnetotail during more quiet magnetospheric conditions.

[3] Several inner magnetosphere missions have recorded the presence of various fine energy structures in the ring current region. These structures, first observed by Smith and Hoffman [1974] in data from Explorer 45, have been referred to as "nose-like" structures, because of the shape of the created features in the energy-time ion spectrograms. These features are characterized by a deeper inward penetration of particles coming from the tail at a given energy (typically a few $\mathrm{keV}$ ), and then spreading to both higher and lower energies at larger $L$ shell values. This global "nose structure" denomination can however regroup several dif-

\footnotetext{
${ }^{1}$ Centre d'Etude Spatiale des Rayonnements, Université de Toulouse, UMR5187, Toulouse, France.

${ }^{2}$ UMR5187, CNRS, Toulouse, France.

${ }^{3}$ State Key Laboratory of Space Weather, CSSAR, CAS, Beijing, China.

${ }^{4}$ VEGA, ESA, Villafranca, Spain.
}

Copyright 2009 by the American Geophysical Union. 0148-0227/09/2007JA012757\$09.00 ferent formation processes. The shape these structures take, as observed in the energy-time ion spectrograms, depends also strongly on the orbit of the spacecraft. In some cases an elongation of the nose-like structure is produced, and in an energy-time ion spectrogram it resembles then to a fine energy band (cf. for example Figure 2).

[4] A first explanation for the formation of the nose structure was given by Ejiri [1978]. The seed population of these structures comes from plasma issued from the neartail plasma sheet, which is injected inward by a relatively weak convective electric field. There the ions, which follow complex trajectories, are subject to the antagonistic effects of the magnetic field gradient and curvature drift (westward drift, particle energy dependent), and of the corotation electric field (eastward drift, energy independent). There is thus an energy where these two oppositely directed drift mechanisms compensate each other, which depends on the location (geocentric distance, magnetic local time (MLT)) and on the magnetospheric activity level, and which for a geocentric distance of the order of $4 R_{E}$ is typically between 6 and $9 \mathrm{keV}$ [De Michelis et al., 1997]. The resulting stagnation drastically increases the residence time of the ions in the inner magnetosphere, for this narrow energy range, resulting in an enhanced loss of ions in this energy range due to charge exchange collisions with the exosphere population [Kovrazhkin et al., 1999].

[5] Another type of observed nose structures, called also stationary nose structures, were successfully reproduced by Shirai et al. [1997] using an ion drift trajectory model. These are the consequence of the open/close character of 
the particle orbits: the corotation electric field is sufficient to close, at the observation point, the orbit around the Earth of low-energy particles which are drifting eastward. Also, the magnetic field gradient is strong enough to close the orbits of high-energy particles which are drifting westward. As a consequence, for these energies, particles are not continuously supplied from the tail region. However, particles with intermediate energies are on open orbits (neither the corotation electric field nor the magnetic field gradient permit to close their orbits around the Earth), creating these nose structures.

[6] Double nose structures (referred also as "split nose"), were studied by Buzulukova et al. [2003]. They were simulated by the authors and interpreted as the result of a superposition in the spectrograms of an initially single stationary nose together with a gap described and analyzed by Lennartsson et al. [1979]. This gap, which was observed in the morning and premorning sector, is created at energies within the nose energy range, leading to a split of the stationary nose into two parts.

[7] Multiple nose formation has also been interpreted as the result of two combined processes: a change in the convection electric field together with a change in the distribution function of the source to explain the low-energy particles features [Ebihara et al., 2004].

[8] Nose-like structures have been previously observed in the Explorer 45 ion data [Ejiri et al., 1980], in the Akebono data [Shirai et al., 1997], in the Interball-Auroral data [Kovrazhkin et al., 1999; Buzulukova et al., 2003], in the Polar CAMMICE data [Ganushkina et al., 2000], in the CRRES data [Huang et al., 2005], and in the FAST and Equator-S data [Angelopoulos et al., 2002], where coordinated $\mathrm{H}^{+}$observations were possible for an event that occurred during the late recovery phase of a storm. More recently the Cluster Cluster Ion Spectrometry (CIS) data have allowed a systematic survey of these structures, and a detailed statistical analysis of their characteristics and their distribution was performed that included also a modeling of their formation [Vallat et al., 2007], using a numerical particle trajectory simulation code for $\mathrm{H}^{+}$ ions [Ganushkina et al., 2005]. Many features observed in the Cluster CIS data have been accurately reproduced, taking into account the long formation time $(>10 \mathrm{~h})$ to populate the ring current region, starting from the seed population in the nearEarth magnetotail, and the changing convection electric field during that period. However, the most complex of these structures, as for example the triple noses, are more challenging and the details of their formation process are not fully understood [Jordanova, 2005; Vallat et al., 2007, Buzulukova and Vovchenko, 2008]. Understanding the formation and the characteristics of these compound structures is part of the puzzle for understanding the dynamics of the inner magnetosphere, a critical area for energy dissipation in the earth's magnetosphere.

[9] Here we study some events for which coordinated ion measurements are available, simultaneously acquired onboard the Cluster and Double Star spacecraft. As described in the following section, these spacecraft, at a given epoch, probe the ring current in opposite MLT sectors. Furthermore, the Cluster spacecraft give a latitudinal profile of the ring current region, whereas the Double Star Tan Ce 1 (TC-1) spacecraft provides the profile along the equatorial plane, across $L$ shells. This allows, for the first time, the analysis of the large-scale characteristics of the fine energy structures observed in the ring current region, under various magnetospheric conditions: our study includes events where coordinated ion measurements were obtained during quiet conditions, during disturbed geomagnetic conditions, and during an intense storm. Moreover, the Cluster instrumentation provides these measurements resolved for various ion species $\left(\mathrm{H}^{+}, \mathrm{He}^{+}, \mathrm{O}^{+}\right)$.

[10] We note also that the Cluster four closely spaced spacecraft configuration allows, in addition to the particle measurements, a direct measurement of the current density in the ring current, using simultaneous four-point magnetic field measurements and applying the curlometer technique [Robert and Roux, 1993; Dunlop et al., 2002]. However, the application of this method in the ring current requires spacecraft separations not exceeding typically $\sim 100 \mathrm{~km}$ [Vallat et al., 2005], a tetrahedron configuration which was achieved only during the period February-June 2002, i.e., well before the Double Star spacecraft launch. This method cannot thus be used in the present coordinated ClusterDouble Star observations of the ring current, where the Cluster spacecraft separation was much larger.

\section{Cluster and Double Star Orbits and Instrumentation}

[11] The Cluster mission is based on four identical spacecraft launched in 2000 on similar elliptical polar orbits with a perigee at about $4 R_{E}$ and an apogee at $19.6 R_{E}$ [Escoubet et al., 2001]. This allows Cluster to cross the ring current region, the radiation belts and the outer plasmasphere, from south to north, during every perigee pass, and to obtain their latitudinal profile, following almost the same flux tube [Vallat et al., 2005; Dandouras et al., 2005]. Moreover, because of the annual precession of its orbit, Cluster is crossing the equator at all MLT ranges over a year.

[12] Since 2004 the Chinese Double Star TC-1 and TC-2 spacecraft have provided two additional points of measurement, on a larger scale: the Cluster and Double Star orbits are such that the spacecraft are almost in the same meridian, allowing conjugate studies. The equatorial spacecraft (TC-1) was launched into an elliptical orbit of $1.09 \times 13.4 R_{E}$, inclined at $28.5^{\circ}$ to the equator. This enabled it to investigate the Earth's magnetic tail (or dayside outer magnetosphere), and then to cut through the inner magnetosphere and get even below the inner radiation belt. TC-1 measurements provide thus the profile across $L$ shells of the ring current populations close to the magnetic equator. TC-2 was launched into a polar orbit $\left(1.1 \times 6.8 R_{E}, \sim 90^{\circ}\right.$ inclination $)$. The TC-1 spacecraft reentered the atmosphere on 14 October 2007.

[13] Since the orbits have been designed to have the Cluster and TC-1 apogees almost in the same meridian (Figure 1), and Cluster probes the ring current during the perigee passes whereas TC-1 probes it at about midcourse between its apogee and its perigee, the Cluster and TC-1 spacecraft can, when their passes are synchronized, simultaneously investigate the ring current in opposite MLT sectors.

[14] The Cluster Ion Spectrometry (CIS) experiment on board Cluster consists of the two complementary spectrometers Composition and Distribution Function Analyzer (CODIF) and Hot Ion Analyzer (HIA), and provides the three-dimensional ion distribution functions (about 0 $40 \mathrm{keV} / \mathrm{q}$ ) with an one spacecraft spin (4 s) time resolution 


\section{Tail crossings}

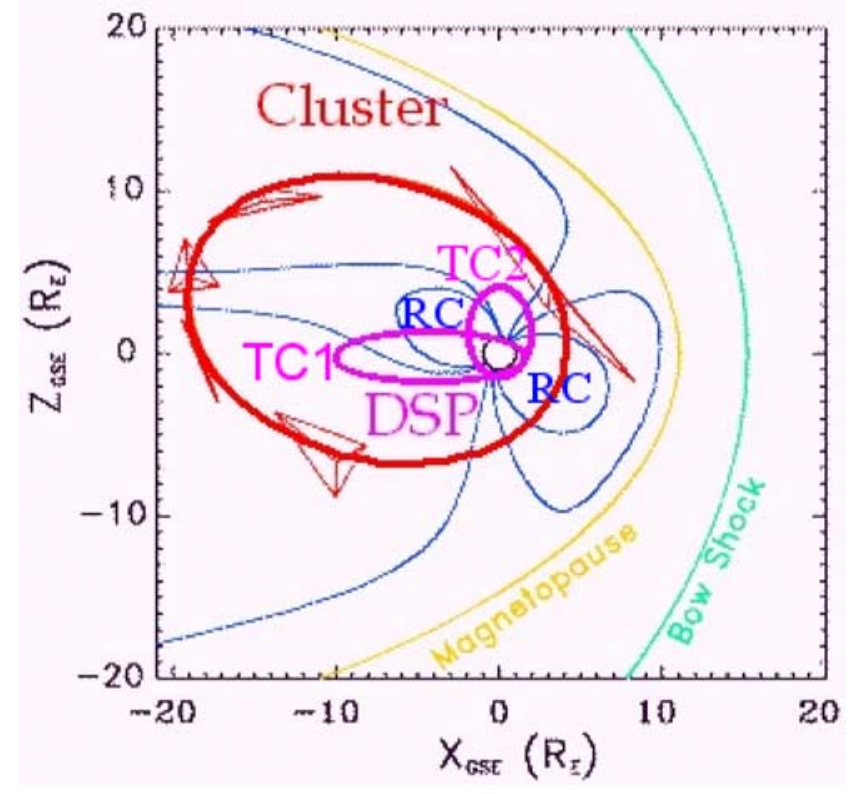

Figure 1. Orbit of Double Star and Cluster during the magnetotail crossings. The Cluster orbit is given in red and the orbits of the two Double Star (DSP) satellites, i.e., the equatorial TC-1 and the polar TC-2, are in purple. RC is the ring current region.

[Rème et al., 2001]. Furthermore, the mass-resolving spectrometer CODIF provides the ionic composition of the plasma separately for the major magnetospheric species $\left(\mathrm{H}^{+}, \mathrm{He}^{++}, \mathrm{He}^{+}\right.$, and $\left.\mathrm{O}^{+}\right)$, from the thermal energy to about $40 \mathrm{keV} / \mathrm{q}$, covering thus a substantial part of the ring current energy range [Williams, 1987]. In addition CODIF is equipped with a Retarding Potential Analyzer (RPA), which allows more accurate measurements in the about $0.7-25 \mathrm{eV} / \mathrm{q}$ energy range, with respect to the spacecraft potential, covering the plasmasphere energy domain. The operation on CODIF of the RPA mode and of the normal magnetospheric modes (which provide a $25 \mathrm{eV} / \mathrm{q}$ to $40 \mathrm{keV} / \mathrm{q}$ energy range) is mutually exclusive. The magnetic field data used come from the FGM (Fluxgate Magnetometer) experiment on board Cluster [Balogh et al., 2001], and the spacecraft potential data from the Electric Field and Wave (EFW) experiment on board Cluster [Gustafsson et al., 2001].

[15] The HIA (Hot Ion Analyzer) instrument on board the Double Star TC-1 spacecraft is an ion spectrometer nearly identical to the HIA sensor of the CIS instrument on board the four Cluster spacecraft. This instrument has been specially adapted for TC-1. It measures the 3-D distribution functions of the ions between $5 \mathrm{eV} / \mathrm{q}$ and $32 \mathrm{keV} / \mathrm{q}$ without mass discrimination [Rème et al., 2005]. The Double Star magnetic field data used come from the FGM (Fluxgate Magnetometer) experiment on board TC-1 [Carr et al., 2005].

\section{Observations and Analysis}

\subsection{Quiet Time Event (12 October 2004)}

[16] On 12 October 2004, the ring current activity conditions were very quiet, and the Dst index had small absolute values during the whole day. The Cluster spacecraft crossed the ring current from south to north in the 0900 MLT sector. Figure 2 shows the CODIF and HIA data from Cluster SC1 (spacecraft 1), for the main ion species. As shown in Figure 2 (second panel) (CODIF $\mathrm{H}^{+}$energy-time spectrogram), the spacecraft, inbound from the southern lobe, entered into the plasma sheet boundary layer (PSBL) at $1107 \mathrm{UT}$, as revealed by the highly structured energy beams in the few $\mathrm{keV}$ energy range observed there, which are typical of the PSBL [e.g., Keiling et al., 2004]. At around 1150 UT the spacecraft encountered a clear boundary and entered into the ring current, at an $L$ shell value [Mcllwain, 1961] $>10$. The ring current is revealed by the presence of strong fluxes of high-energy $(>10 \mathrm{keV})$ trapped ions, typically observed by CODIF in this region and identified as part of the ring current population [Vallat et al., 2004, 2005]. At these energies the westward gradient and curvature drift in the inner magnetosphere is much higher than the eastward corrotation velocity, resulting in a net westward transport of the ions. Their pitch angle distribution, as shown in Figure 2 (first panel), evolves toward a $90^{\circ}$ centered distribution observed around the magnetic equator $(\sim 1400$ UT).

[17] The ion energy-time spectrograms acquired in the ring current show at least two well-formed banded structures, one around $1 \mathrm{keV}$ and one at $10-30 \mathrm{keV}$. A third, fainter ion structure can also be observed in the $\mathrm{H}^{+}$data, at $\sim 3 \mathrm{keV}$. Note that the main $10-30 \mathrm{keV}$ banded structure appears in the same energy range for the $\mathrm{H}^{+}, \mathrm{He}^{+}$and $\mathrm{O}^{+}$ data, although the energy resolution of the $\mathrm{He}^{+}$and $\mathrm{O}^{+}$ measurements is lower. The high-resolution $\mathrm{H}^{+}$measurements reveal also that this $10-30 \mathrm{keV}$ structure is not homogeneous in energy, but presents a finer structure, being composed of two banded structures. A total of four structures can thus be identified in the $1-40 \mathrm{keV}$ energy range.

[18] Between 1320 and 1500 UT the CIS data suffered a strong background due to penetrating particles from the radiation belts, appearing as a high counting rate in all energies. This background is stronger for HIA, whereas CODIF benefits from the time-of-flight measurement technique that requires, for each ion, the detection of two signals in a valid time-of-flight window, and which allows the rejection from the counting statistics of a high number of penetrating particles from the radiation belts. This background rejection is even more efficient for the $\mathrm{H}^{+}$ions detected by CODIF (compared to the $\mathrm{O}^{+}$ions), because of the shorter time-offlight window of the first ones.

[19] As shown in Figure 2, the Cluster SC1 exit from the ring current region was observed at 1543 UT ( $L$ shell value $>10)$, and the spacecraft went then in the northern plasma sheet boundary layer and then in the northern lobe.

[20] During this event, CIS onboard Cluster SC4 was operated in the RPA mode, covering the plasmasphere energy domain [Dandouras et al., 2005]. As shown in Figure 3, where the SC1 CIS data are shown again for reference in Figure 3 (top), and the SC4 CIS-RPA data are in Figure 3 (middle), Cluster SC4 in its inbound leg started detecting diffuse low-energy $\mathrm{H}^{+}$populations at about $1200 \mathrm{UT}$. At about 1325 UT a more dense population appeared in the data, but this is also a region where some background due to penetrating particles from the radiation belts is present. In Figure 3 (bottom) the negative of the spacecraft potential 


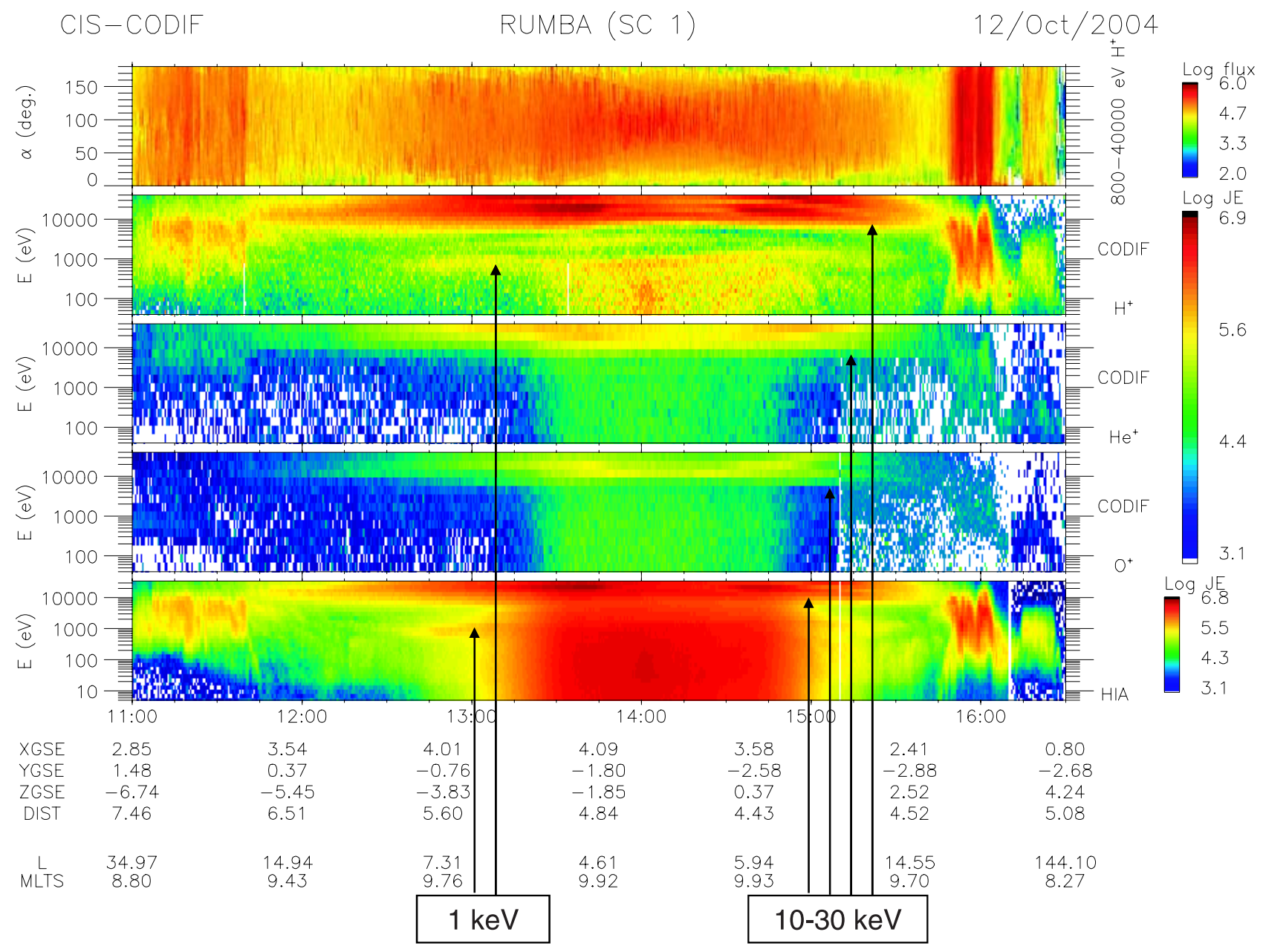

Figure 2. Cluster SC1 ion data for the 12 October 2004 perigee pass. (first panel) Pitch angle plot for $\mathrm{H}^{+}$CODIF data in the $800-40 \mathrm{keV}$ energy range and in differential particle flux units (ions $\mathrm{cm}^{-2} \mathrm{~s}^{-1} \mathrm{sr}^{-1}$ $\mathrm{keV}^{-1}$ ); (second-fourth panel) CODIF omnidirectional energy-time spectrograms in particle energy flux units $\left(\mathrm{keV} \mathrm{cm}^{-2} \mathrm{~s}^{-1} \mathrm{sr}^{-1} \mathrm{keV}^{-1}\right)$ separately for $\mathrm{H}^{+}, \mathrm{He}^{+}$, and $\mathrm{O}^{+}$ions; (fifth panel) HIA omnidirectional energy-time spectrogram in particle energy flux units (no mass discrimination). The spacecraft coordinates (GSE system), geocentric distance in $R_{E}, L$ shell value, and MLT are given. The observed nose-like structures are indicated by the arrows.

value is plotted, for Cluster SC1 (in black) and SC4 (in magenta), as measured by the EFW electric field experiment. Spacecraft potential is a very good proxy of the total electron density [Pedersen et al., 2001; Darrouzet et al., 2004]: the high flux of ambient electrons in the plasmasphere brings the spacecraft potential to only a few volts positive relative to the plasma; in the lobes, however, the electron flux is very low and the spacecraft goes very positive (to $+50 \mathrm{~V}$ or more), because of photoelectron emission. As confirmed by the spacecraft potential values, both spacecraft encountered, after about 1200 UT, a very diffuse plasmasphere boundary layer with a gradual increase of plasma density, which is typical of extended periods of relatively quiet geomagnetic conditions. Between about 1330 and 1455 UT the density values show a plateau, where the spacecraft potential was $+3 \mathrm{~V}$, typical of the outer plasmasphere. The CIS-RPA data, plotted in Figure 3, have been corrected for this $+3 \mathrm{~V}$ spacecraft potential value. The exit from the plasmasphere is more asymmetric and a short density enhancement was observed by both CIS-RPA and EFW, after about 1505 UT, before gradually getting out. We note also that the SC1-SC4 separation distance was $\sim 1050 \mathrm{~km}$, SC1 slightly leading, and the EFW data confirm that the traversal of this diffuse plasmasphere was almost simultaneous by both spacecraft.

[21] From these data it can hence be deduced that the banded structures that were observed by the Cluster spacecraft (cf. Figure 2 and Figure 3 (top)) during this quit conditions event were extending over a diffuse plasmasphere, covering a wide range of plasma densities on either side of the diffuse plasmaspheric boundary.

[22] The Double Star TC-1 spacecraft went through perigee at $1000 \mathrm{UT}$, i.e., $4 \mathrm{~h}$ ahead of Cluster. Given the very quiet conditions during that period, and which prevailed for more than $24 \mathrm{~h}$, we can consider that the ring current configuration was the same between the Double Star TC- 1 and the Cluster observations. In the inbound leg of its orbit, TC-1 was in eclipse until 0738 UT, which explains the data gap in the TC-1 HIA data until this time, shown in Figure 4. Just after the end of the eclipse HIA was mea- 

CIS \& EFW
$12 / 0 \mathrm{ct} / 2004$

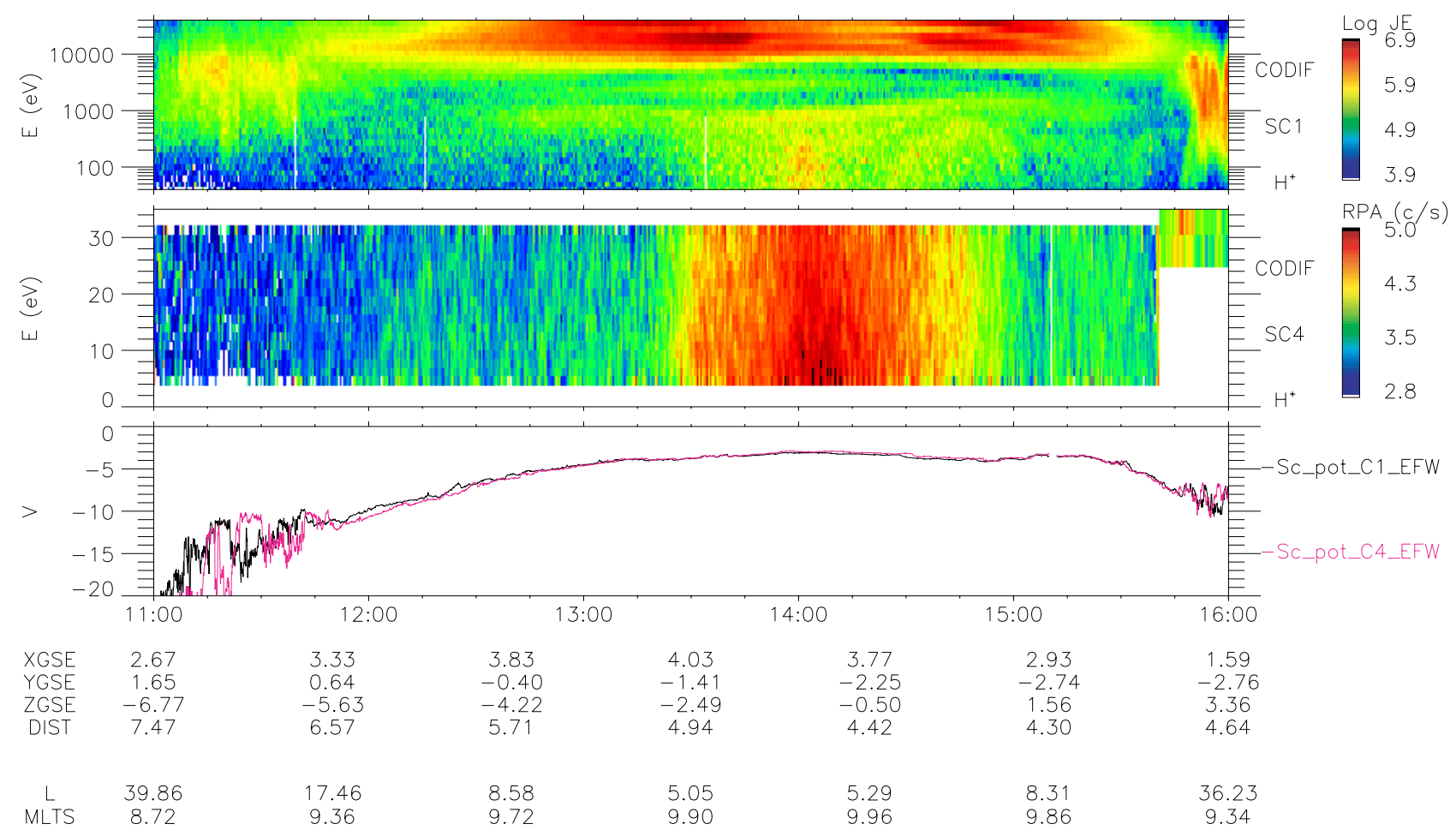

Figure 3. Cluster SC1 and SC4 data for the 12 October 2004 perigee pass through the plasmasphere. (top) CODIF ( $\mathrm{SC} 1)$ omnidirectional $\mathrm{H}^{+}$energy-time spectrogram in particle energy flux units $\left(\mathrm{keV} \mathrm{cm}^{-2}\right.$ $\mathrm{s}^{-1} \mathrm{sr}^{-1} \mathrm{keV}^{-1}$ ) for $\mathrm{H}^{+}$(normal mode), (middle) CODIF (SC4) omnidirectional $\mathrm{H}^{+}$energy-time spectrogram in particle counts per second in the RPA mode (low-energy ions detection, operated until $1540 \mathrm{UT}$ ), and (bottom) negative of the spacecraft potential measured by the EFW experiment (SC1 and SC4, in black and magenta, respectively). The later is a proxy of the plasma density.

suring ring current populations. A second data gap appears in the TC-1 HIA data between 0935 and 1028 UT (around perigee), when the instrument was switched in a standby mode for the traversal of the inner radiation belt. At the outbound leg of the orbit, just after the exit from the inner belt, the TC-1 spacecraft remained into in the ring current until 1457 UT, at an $L$ shell value of 9. This outbound leg was in the evening sector (2000 MLT). However, as shown in Figure 4, TC-1 recorded the same main $10-30 \mathrm{keV}$ noselike structure as the banded ion observed by Cluster in the diametrically opposite MLT sector. Closer to perigee and deep inside the ring current region, i.e., at $L$ shell values 3.5-4.5, TC-1 observed subkeV energy-dispersed wedgelike ion structures [Yamauchi et al., 2005, 2006].

[23] It is also worth noting that, just after the HIA switch on to an operational mode at 1028 UT, the data indicate the presence there of a fine structured double nose $(10-20 \mathrm{keV}$ and $>25 \mathrm{keV}$ ), which seems to extend deeper toward the slot region, between the inner and the outer radiation belt. Since however the data gap there does not allow an accurate identification, the presence of such nose structures extending within the slot region will be discussed in section 3.4. Note, also, in Figure 4, that the Double Star HIA data suffer from less background from penetrating particles than the Cluster HIA data (cf. Figure 2), because of the extra shielding that was fitted on the Double Star HIA instrument.
[24] The ring current boundary identifications in the Cluster and Double Star TC-1 data allow also to delimit the largescale geometry of the ring current (Figure 5). The projection is performed on a magnetosphere plot based on Tsyganenko's [1989] magnetic field model. In the dayside and at the high latitudes surveyed during this quiet time event by Cluster the ring current extends out to $L>10$. In the nightside, however, and at the equatorial latitudes surveyed during this event by TC- 1 , the ring current is limited out to $L \approx 9$, where a clear transition to the magnetotail plasma sheet is observed. Although at the high magnetic latitudes on which the Cluster spacecraft encounter the ring current boundary the physical meaning of the $L$ parameter becomes less accurate, since it depends on the magnetic model used to trace the field line down to the magnetic equator, it still gives a reasonable estimate of the topology of the magnetic flux tube in which the detected particles are trapped.

\subsection{Disturbed Time Event (3 April 2004)}

[25] On 3 April 2004, the magnetospheric conditions were initially quiet. However, following a sudden compression at 1410 UT (as identified on the SYM- $H$ index, not shown), a storm main phase was observed starting at $\sim 1600$ UT, at 1700 UT the Dst index was $-29 \mathrm{nT}$ and at $1900 \mathrm{UT}$ it had already a value of $-76 \mathrm{nT}$ (Figure 6). The Cluster spacecraft went through perigee at around 1300 UT, i.e., well before 


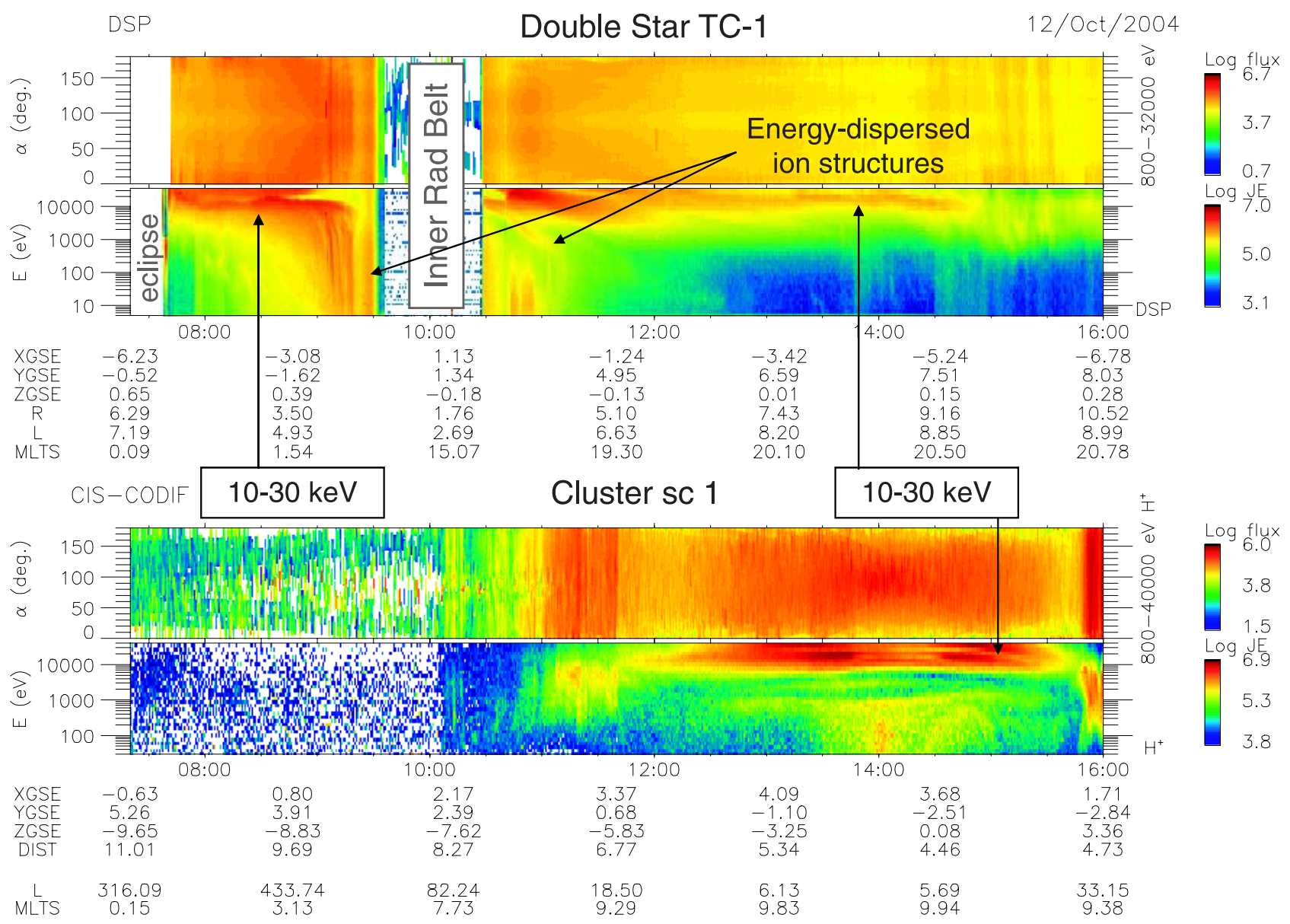

Figure 4. (top) Double Star TC-1 ion data (HIA instrument) for the 12 October 2004 perigee pass, combined with (bottom) Cluster $\mathrm{SC} 1 \mathrm{H}^{+}$data (CODIF instrument). For each spacecraft, pitch angle plot in differential particle flux units (ions $\mathrm{cm}^{-2} \mathrm{~s}^{-1} \mathrm{sr}^{-1} \mathrm{keV}^{-1}$ ), energy-time spectrogram in particle energy flux units $\left(\mathrm{keV} \mathrm{cm}^{-2} \mathrm{~s}^{-1} \mathrm{sr}^{-1} \mathrm{keV}^{-1}\right)$, spacecraft coordinates (GSE system), geocentric distance in $R_{E}$, $L$ shell value, and MLT.

the storm onset. As shown in Figure 7 (top) (CODIF data), Cluster SC4, inbound from the southern lobe, entered into the PSBL at $1125 \mathrm{UT}$, as revealed by the energy-dispersed ion structures [e.g., Keiling et al., 2004], and then entered into the ring current at $\sim 1212$ UT, in the 2200 MLT sector and at an $L$ shell value of $\sim 7$. There it observed two wellformed nose-like structures, one at $7-15 \mathrm{keV}$ and one at 20-30 keV. Note that these appear in the same energy ranges for the $\mathrm{H}^{+}, \mathrm{He}^{+}$and $\mathrm{O}^{+}$data (although the energy resolution of the $\mathrm{He}^{+}$and $\mathrm{O}^{+}$measurements is lower). The exit from the ring current region was observed at $1416 \mathrm{UT}$ ( $L$ shell value of 6.5), and it corresponded to a sharper boundary than in the inbound leg. The storm main phase development started while Cluster was in the northern lobe, at the outbound leg of its orbit. The storm-associated magnetospheric compression, which was already initiated at 1410 UT while Cluster was in the inner magnetosphere, resulted in an "accelerated" exit into the magnetosheath, at $\sim 1825$ UT (8.4 $R_{E}$ geocentric distance in the 0930 MLT sector), following a traversal through the northern cusp.

[26] CIS did not operate in the RPA mode during this event. The plasmasphere position can be deduced, however, from the spacecraft potential, measured by EFW (Figure 7 (top)). In contrast to the diffuse plasmasphere boundary observed during the 12 October 2004 event, a very sharp plasmapause was crossed here, inbound at 1249 UT and outbound at 1352 UT. As shown in Figure 7, the nose-like structures were detected both inside and outside the plasmasphere.

[27] The Double Star TC-1 spacecraft went through perigee at 1630 UT. Its inbound leg was also during still quiet magnetospheric conditions, and as shown in Figure 7 (bottom) (HIA instrument), the TC-1 spacecraft entered into in the ring current at $1145 \mathrm{UT}$, at an $L$ shell value of 9. There $(\mathrm{MLT} \approx 11)$, it recorded the same two well-formed banded structures as the ones observed by Cluster in the diametrically opposite MLT sector: one structure at $7-15 \mathrm{keV}$ and one at $20-30 \mathrm{keV}$. The increased ion fluxes observed by TC-1 starting from 1410 UT are just background due to penetrating particles from the outer radiation belt. At perigee, between 1555 and 1658 UT, the HIA experiment was as usually switched in a standby mode for the traversal of the inner radiation belt. When, just after the exit of this belt, the experiment was again operational, it detected a ring current population dominated by freshly injected ions, as revealed by the bursty nature of the data which show a close succession of several injection events, and which present 


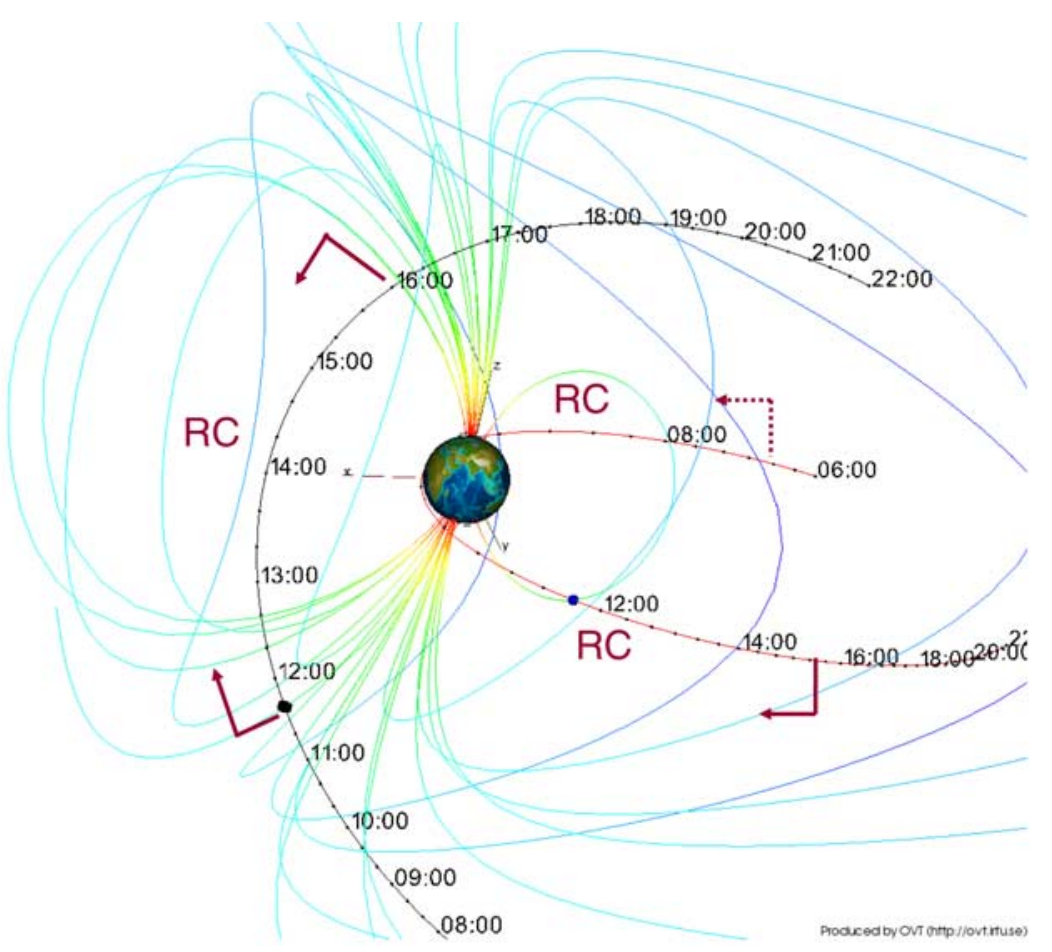

Figure 5. Cluster SC1 orbit (in black) and Double Star TC-1 orbit (in red) for the 12 October 2004 perigee passes, projected on Tsyganenko's [1989] magnetic field model. The segments of the two orbits during which the two spacecraft were in the ring current are delimited by the arrows. Orbit Visualization Tool (OVT) plot courtesy of the OVT team.

almost no energy dispersion. The well-formed banded structures, observed at the inbound leg just before the storm onset, and which require a formation time of the order of $\sim 15 \mathrm{~h}$ or more with quiet magnetospheric conditions [Kovrazhkin et al., 1999; Vallat et al., 2007], were completely "washed out" by the freshly injected ions, following the storm onset. These injection signatures do not also allow the identification of a clear ring current boundary, and the data show a period of merged ring current and very active morning sector plasma sheet. The spacecraft then, after a brief transition through the lobe (1933 UT), entered into the magnetosheath at 1945 UT.
[28] Figure 8 shows the Cluster and Double Star TC-1 ring current boundary identifications for this event, projected on a magnetosphere plot based on Tsyganenko's [1989] magnetic field model. In the nightside and at the high latitudes surveyed during this event by Cluster (quiet time period) the ring current extends out to $L \approx 7$, bounded by the plasma sheet/PSBL at its southern part and presenting a sharp transition to the lobe in its northern part. The observed positions of the plasmapause, for the inbound and outbound leg of the Cluster orbit, are also marked in Figure 8. In the dayside, and at the equatorial latitudes surveyed during this

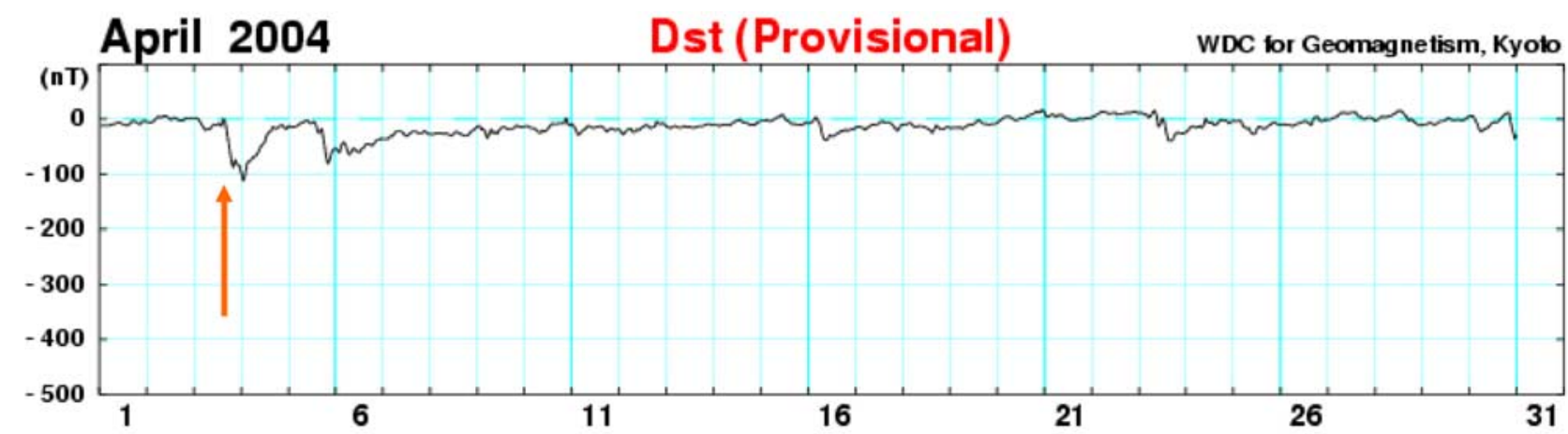

Figure 6. Dst index values for April 2004. On 3 April 2004, the onset of a magnetic storm was recorded while the Double Star TC-1 spacecraft was going through perigee, and the Dst index passed from $1 \mathrm{nT}$ at $1500 \mathrm{UT}$ to $-51 \mathrm{nT}$ at $1800 \mathrm{UT}$. 


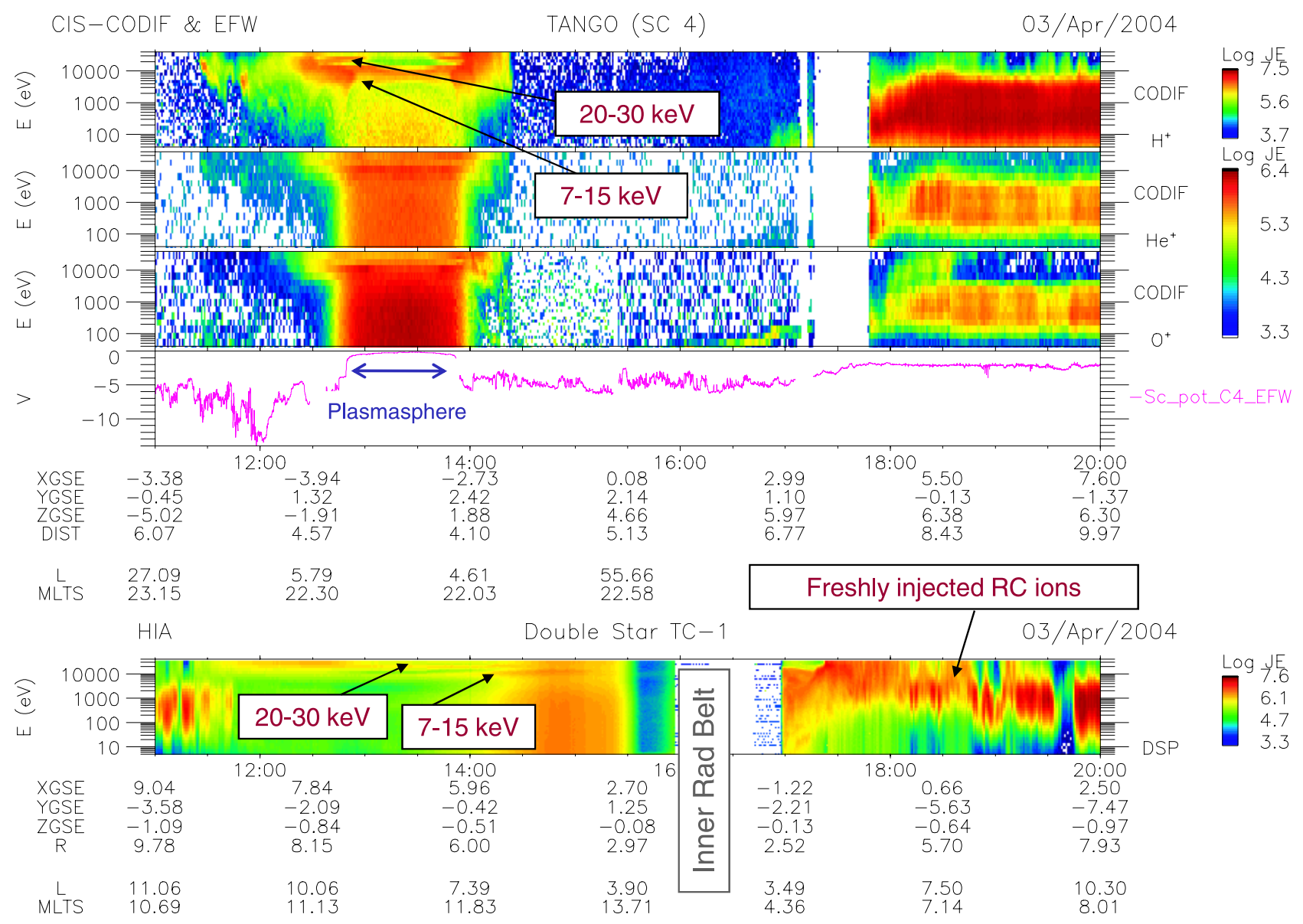

Figure 7. Combined (top) Cluster $\mathrm{SC} 4\left(\mathrm{CODIF} \mathrm{H}^{+}, \mathrm{He}^{+}\right.$, and $\mathrm{O}^{+}$energy-time spectrograms and negative of the spacecraft potential from EFW) and (bottom) Double Star TC-1 (HIA ion energy-time spectrogram) for the 3 April 2004 perigee pass.

event by TC-1, the ring current extends out to $L \approx 9$ (inbound leg, quiet conditions before the storm onset).

\subsection{Intense Storm Event (14-15 December 2006)}

[29] On 13 December 2006, during the descending phase of the 23rd solar cycle and almost into its minimum, a significant X3 solar flare occurred, followed by a strong Earthward oriented CME [Plainaki et al., 2007]. The impact of the ejecta on the Earth's magnetosphere occurred at $\sim 1430$ UT on 14 December 2006, and a solar wind velocity of $930 \mathrm{~km} \mathrm{~s}^{-1}$ was recorded by ACE (data not shown), associated with a jump of the solar wind density to $\sim 10 \mathrm{~cm}^{-3}$ and a southward turning of the IMF. The inner magnetosphere conditions on 14 December were initially quiet, with the exception of a short negative Dst index excursion to $-40 \mathrm{nT}$ at $1800 \mathrm{UT}$. But, at $0000 \mathrm{UT}$ on 15 December, the $D s t$ index intensified rapidly to $-110 \mathrm{nT}$, and at $0700 \mathrm{UT}$ it reached a value of $-147 \mathrm{nT}$ (Figure 9). The recovery phase of this intense storm started at $\sim 1200$ UT on 15 December 2006 , and the ring current activity returned to quiet conditions on 17 December 2006.

[30] The Cluster and Double Star TC-1 orbits during this event are shown in Figure 10. As deduced from the $\mathrm{H}^{+}$spectrogram of Figure 11, Cluster entered into the ring current region, in the morning sector, at $\sim 1350 \mathrm{UT}(L \approx 7)$, while the exit, at the outbound leg of its orbit, was recorded at 1624 UT
( $L \approx 7$ ). Strong background due to penetrating particles from the radiation belts was recorded in both the inbound and the outbound leg of its orbit, at $L$ shell values between $\sim 5.5$ and 6.5. In the CODIF energy range a single nose-like structure was registered, and during this pass its energy evolved from 4 to $12 \mathrm{keV}$ initially to $5-18 \mathrm{keV}$. A similar strong inbound/outbound asymmetry is also observed in the profile of the radiation belts penetrating particles, and it is apparently related to the highly tilted magnetic dipole (Figure 10). It should be noted that the Cluster perigee pass occurred just when the ejecta cloud hitted the magnetosphere, but before the ring current intensification as registered by the $D s t$ index.

[31] The Double Star TC-1 spacecraft went through perigee at 1140 UT (Figure 11 (bottom)). At its inbound leg the HIA instrument recorded an entry into in the ring current at 0330 UT, at an $L$ shell value $>10$ (23 MLT sector). The high-energy resolution of the instrument allows the analysis of the observed banded structure, in the inbound leg and in the interval $6<L<7.5$ (around 0800 UT), in two energy bands, one at $10-14 \mathrm{keV}$ and one above $20 \mathrm{keV}$, its upper limit being beyond the instrument energy domain. At its outbound leg, and after the exit from the heavy radiation belts background zone, i.e., after 1400 UT, the HIA instrument recorded a much more active ring current ion population, with several successive injections, the bulk of the 


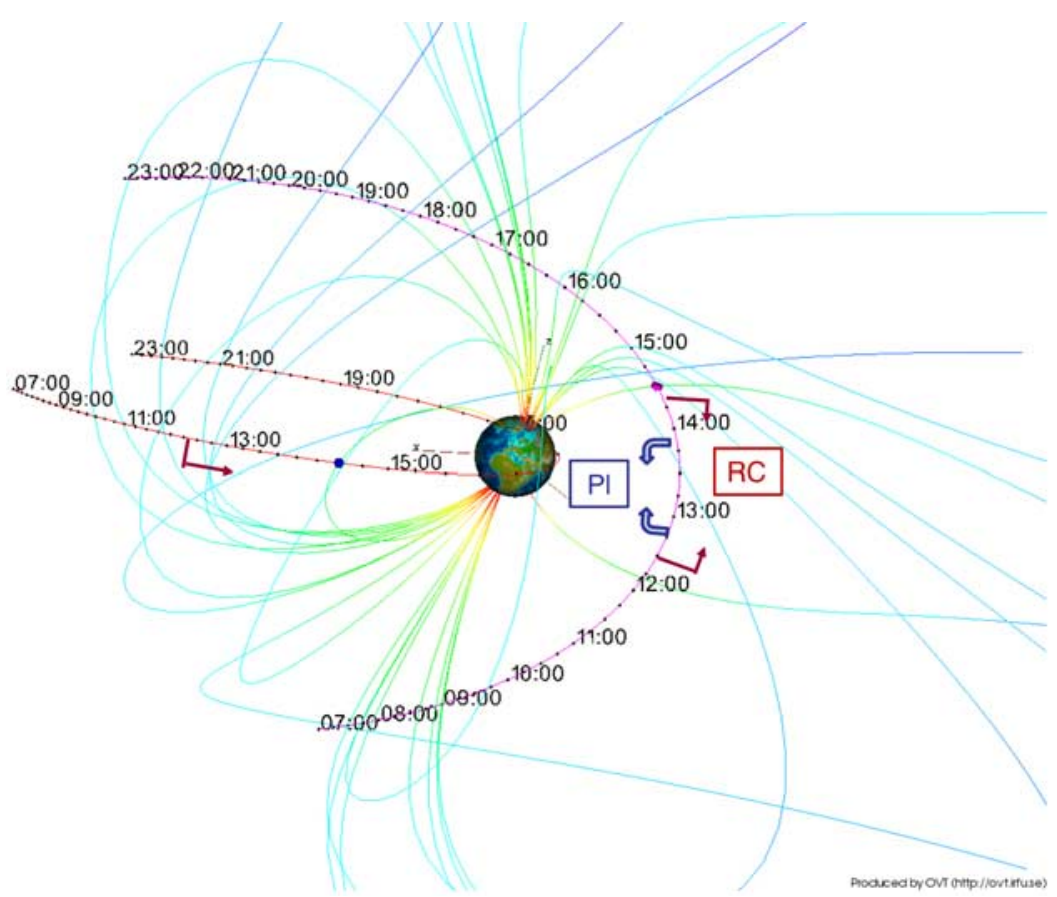

Figure 8. Cluster SC4 orbit (in magenta) and Double Star TC-1 orbit (in red) for the 3 April 2004 perigee passes, projected on Tsyganenko's [1989] magnetic field model. The observed positions of the ring current and the plasmasphere (PL) along the orbit are marked by arrows.

energy being apparently above the instrument energy domain $(E>32 \mathrm{keV})$ and HIA detecting only the lower part of their energy spectrum. As also in the case of the 3 April 2004 disturbed conditions event, there is no clear boundary between the ring current and the plasma sheet, in the HIA energy range. Starting from 1939 UT, and when the TC-1 spacecraft was at a geocentric distance of $8.7 R_{E}$ in the premidnight magnetotail, the instrument recorded a background due to penetrating SEPs (Solar Energetic Particles), which appears as a "green haze" in the energy-time ion spectrogram. Strong energetic $(>10 \mathrm{MeV})$ proton fluxes were also recorded by the GOES-11 satellite, starting from 2230 UT (geostationary orbit, noon sector).

[32] During the next perigee pass, on 15 December 2006, the Double Star TC-1 spacecraft traversed the ring current region while the Dst index absolute value was at the maximum $(D s t=-147 \mathrm{nT}$ at $0700 \mathrm{UT})$. As shown in Figure 12, the HIA instrument recorded a very bursty ion population, which was only the low-energy end of a much more energetic population, well above the instrument energy domain. During that period, the Cluster spacecraft were in the magnetosheath (data not shown).

\subsection{Nose-Like Ion Structures in the Slot Region}

[33] Figure 13 (top) shows the Double Star HIA data during a perigee pass late in the mission, when more risk was allowed and the HIA instrument remained operational through the perigee passes. During this event, occurring under quiet ring current activity conditions and in the noon sector for its inbound leg, the spacecraft traversed first the outer radiation belt, between $\sim 0305$ and $0352 \mathrm{UT}$, and then the inner radiation belt, between $\sim 0412$ and $0430 \mathrm{UT}$, as these two are identified by the background induced from the penetrating particles, the background being much more

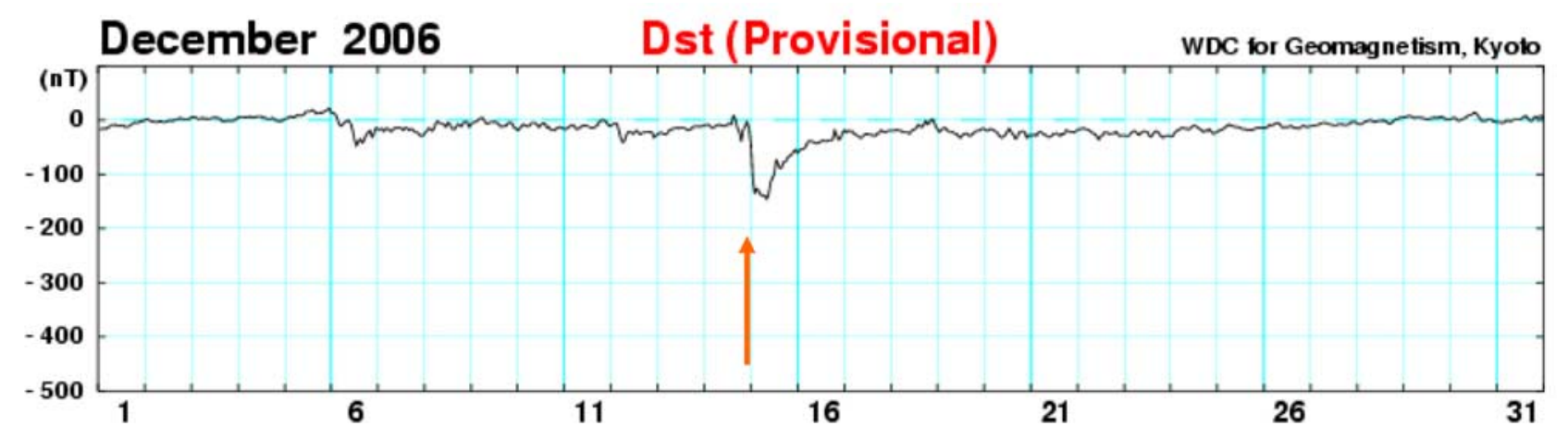

Figure 9. Dst index values for December 2006. On 14 December 2006, the onset of an intense magnetic storm was recorded while the Cluster spacecraft were going through perigee. 


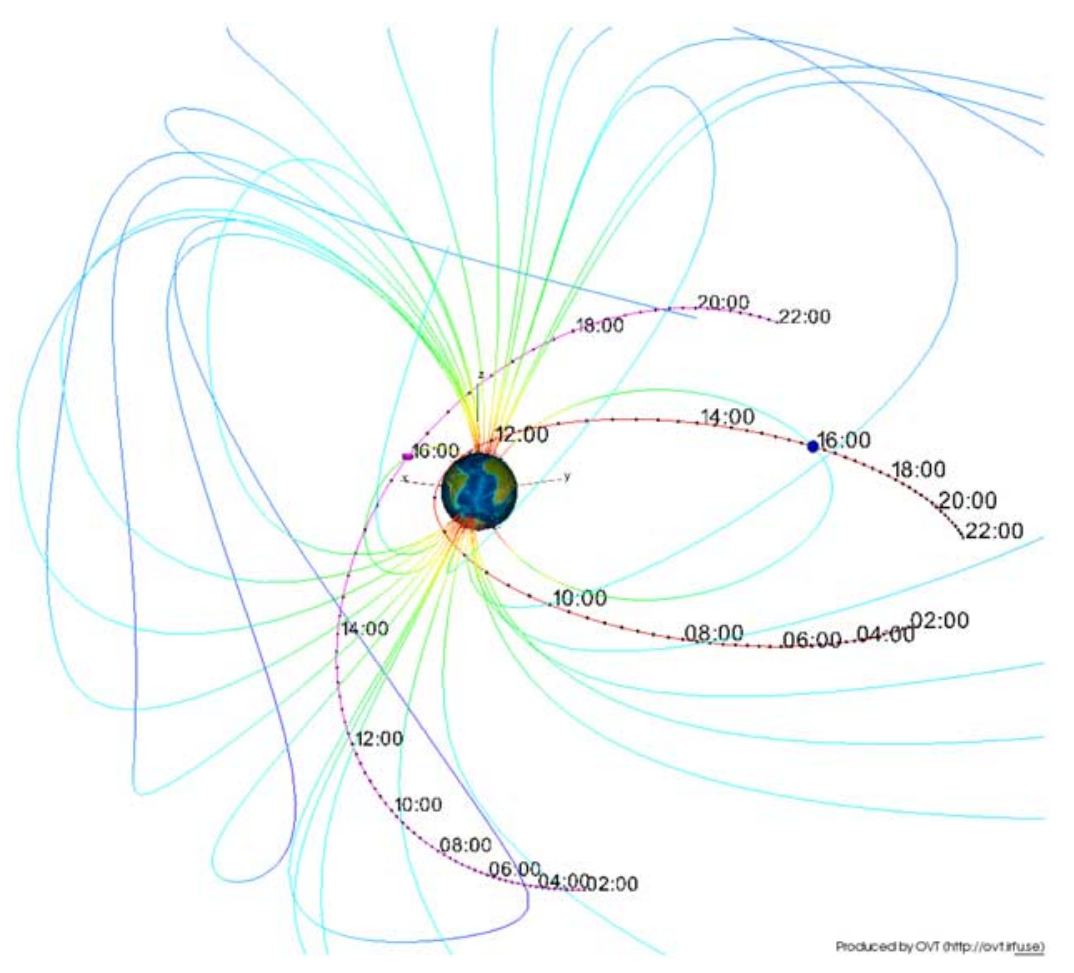

Figure 10. Cluster SC4 orbit (in magenta) and Double Star TC-1 orbit (in red) for the 14 December 2006 perigee passes, projected on Tsyganenko's [1989] magnetic field model.

intense for the inner belt. The perigee occurred below the inner belt, at a region devoid of energetic particles and characterized by the presence of a dense population of lowenergy ions $(<20 \mathrm{eV})$. The short data gap observed close to perigee is due to an eclipse. As the HIA data show, the multiple nose-like structures, identified in the inbound leg before entering in the outer radiation belt, penetrate well inside the slot region, between the inner and the outer radiation belts, down to $L=2.6$.

[34] The presence of such nose-like structures extending within the slot region has been also verified during other test orbits, where the HIA instrument was as well commanded in an operational mode all the way through perigee. For example during the 12 February 2004 perigee pass, HIA recorded a double nose structure (at $13-18 \mathrm{keV}$ and at $>25 \mathrm{keV}$ ), extending down to $L=1.9$, at MLT $=6$ (Figure 13 (bottom)). Although these data suffer from a noisy telemetry link, the identification in them of the inner and the outer radiation belt regions, and of the nose-like structures extending between them, is unambiguous. Note that the slot region is not covered by the Cluster orbit, due to a much higher perigee.

\section{Discussion}

[35] The simultaneous operation of the Cluster and Double Star TC-1 spacecraft and the high-energy resolution of the CIS and HIA experiments allow an extended survey of the inner magnetosphere energetic ion populations. We have analyzed here some typical events, representative of the structures observed in the energetic ion spectra within the ring current region. When an orbital conjunction occurs, the Cluster and Double Star TC-1 spacecraft simultaneously investigate the ring current in opposite MLT sectors, the Cluster spacecraft providing its latitudinal profile whereas TC-1 provides the profile across $L$ shells of the populations close to the magnetic equator, and extends the area covered down to much lower $L$ shell values. This allows a simultaneous almost 3-D coverage of the ring current region. Such conjunctions exist for both quiet time and storm time passes.

[36] In addition to the energetic ion populations, the Cluster spacecraft can also analyze the ion populations of the outer plasmasphere, when the RPA mode is activated. This, however, is not possible with Double Star, because of the absence of an RPA on the TC-1 and TC- 2 spacecraft.

[37] Single nose-like structures, formed by $\mathrm{H}^{+}$ions, have in the past been observed simultaneously in different MLT sectors by using Polar, FAST and Equator-S data, for an event that occurred during the late recovery phase of a storm [Angelopoulos et al., 2002]. However, our study not only confirms the large-scale character of these ion structures in a multievent analysis, but it also shows, for the first time, the large-scale character of multiple nose-like structures, which form in the ring current region, extending in latitude, MLT, and radial distance, covering the outer radiation belt and the slot region, down to $L<2$, and being observed both inside and outside of the plasmasphere. It should be noted that previous observations of nose-like structures, when correlated with the plasmapause position, were limited to the region inside the plasmasphere [Ejiri, 1978].

[38] Although a statistical analysis is not possible, because of the limited number of the Cluster-Double Star orbital conjunctions in the inner magnetosphere, from the few representative events analyzed, covering various magnetospheric conditions, it can be deduced that, for gradient and curvature 


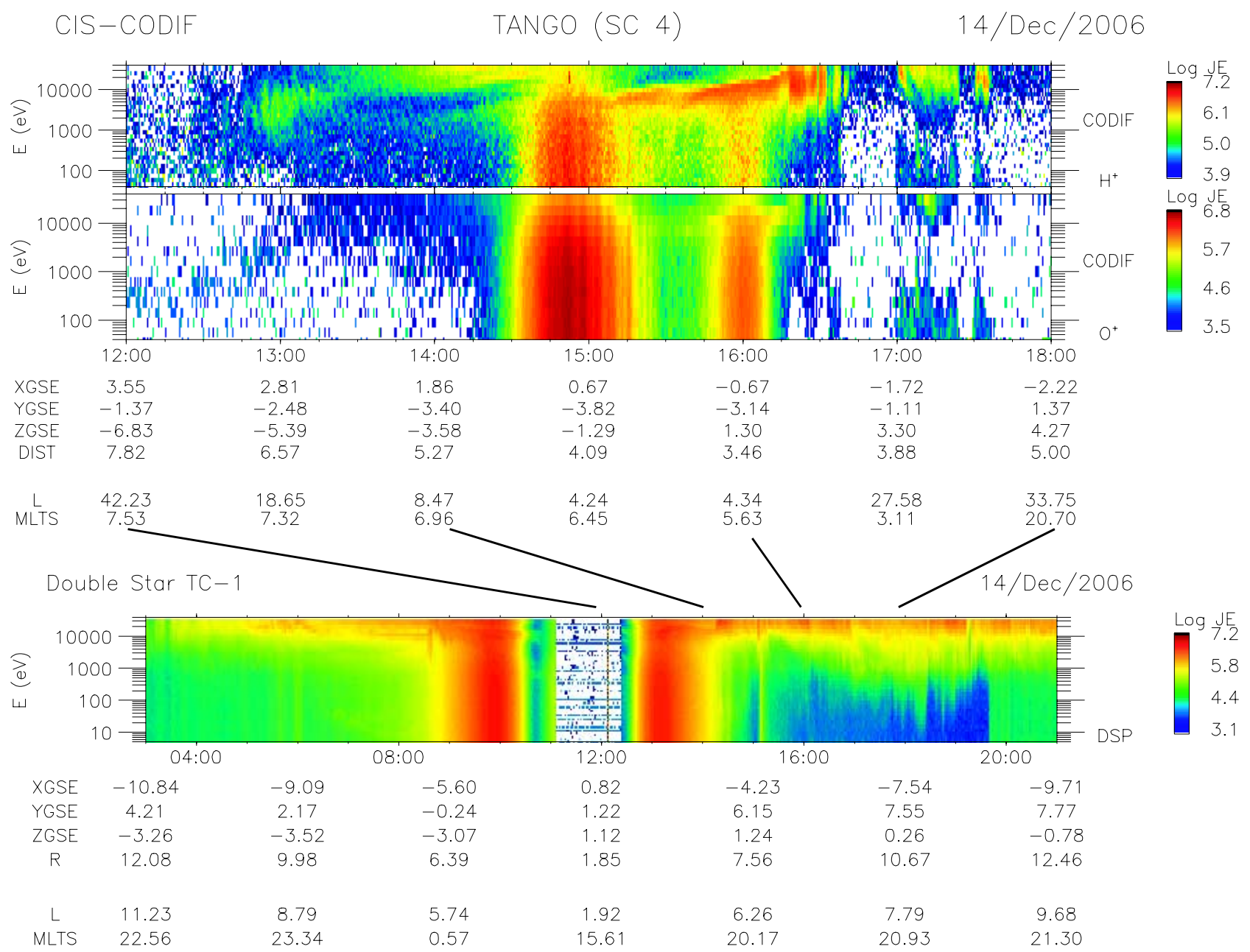

Figure 11. Combined (top) Cluster SC4 (CODIF $\mathrm{H}^{+}$and $\mathrm{O}^{+}$data) and (bottom) Double Star TC-1 (HIA ion data) for the 14 December 2006 perigee pass.

drifting ions (typically $E>7 \mathrm{keV}$ ), these multiple nose-like structures extend in the same energy range in a very large sector. For the 12 October 2004 quiet time event they were simultaneously observed in the morning and evening sector, but there were also other quiet time events during which nose-like structures were simultaneously observed, in the same energy range, in the afternoon and postmidnight sector (e.g., the 7 July 2004 event, data not shown). They thus appear to extend over all azimuthal directions.

[39] As also shown in the analysis of the Cluster data by Vallat et al. [2007], these ion structures observed here by Cluster and Double Star correspond to a very complex energy spectrum, double and some times triple nose structures being present.

Double Star TC-1

$15 / \operatorname{Dec} / 2006$

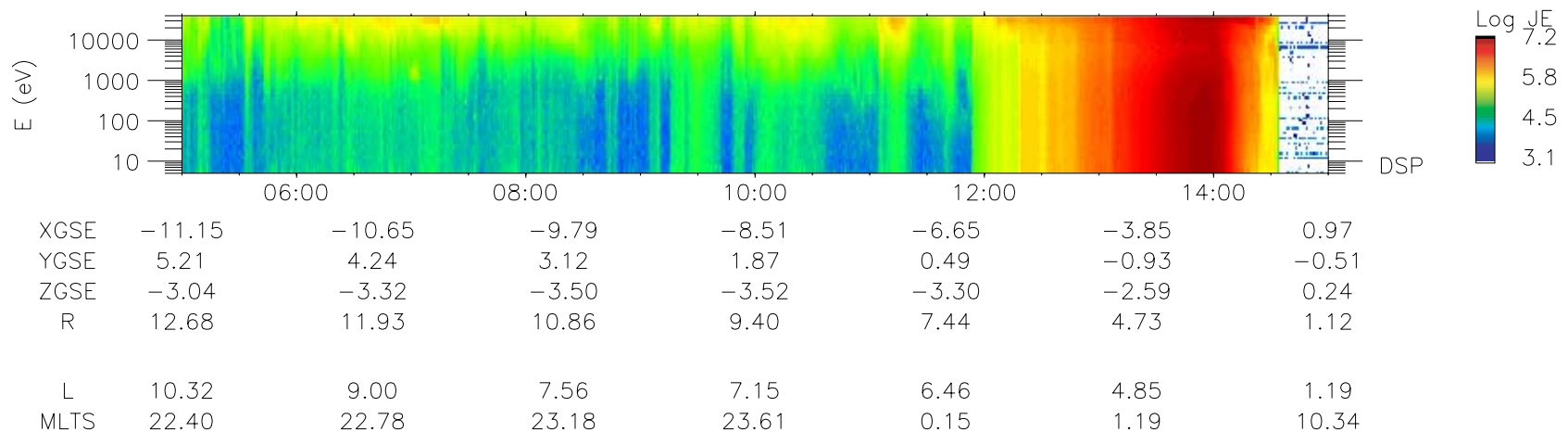

Figure 12. Double Star TC-1 ion data for the 15 December 2006 perigee pass. 


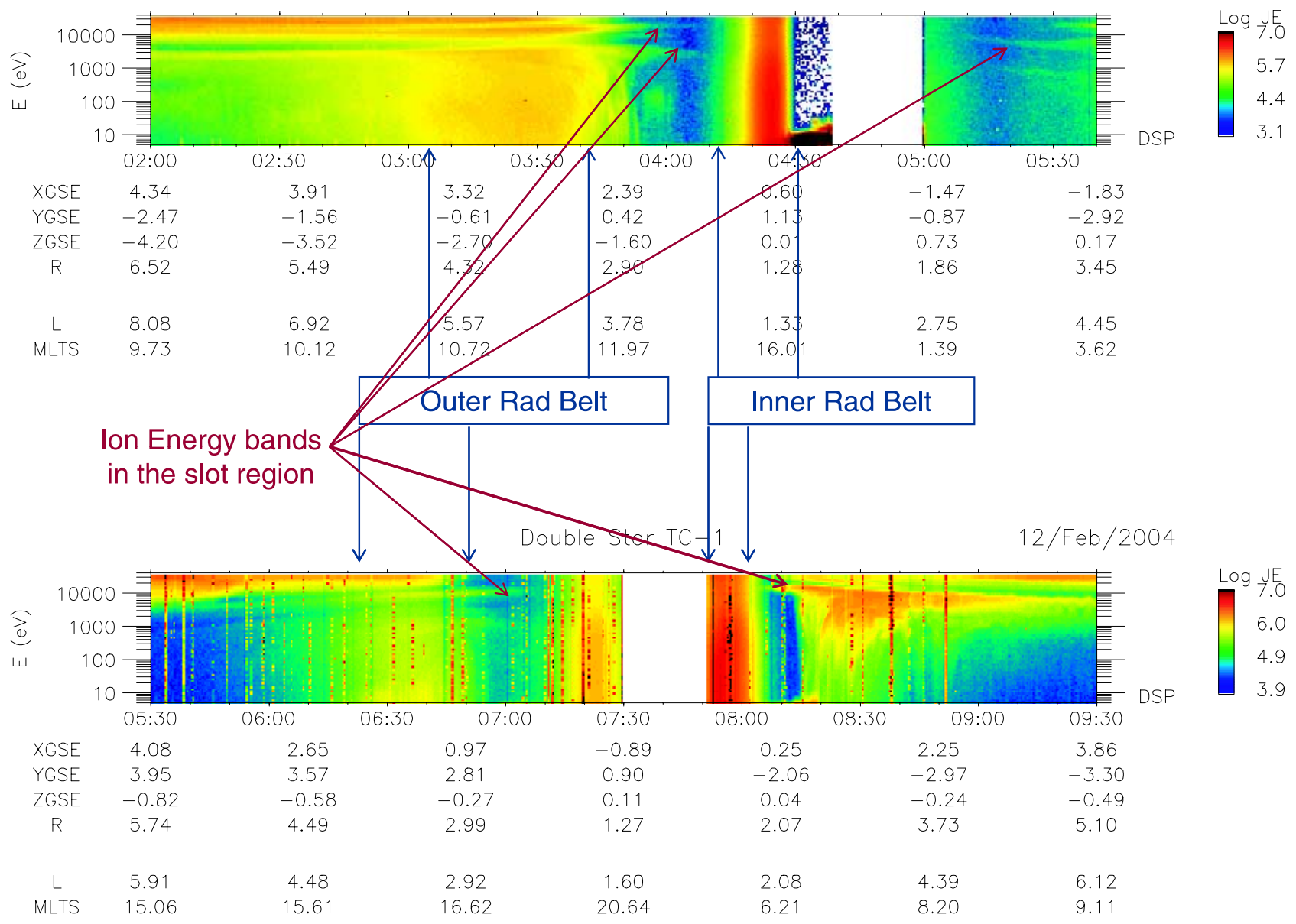

Figure 13. Double Star TC-1 ion data for the (top) 12 August 2007 and (bottom) 12 February 2004 perigee passes. Identification of banded structures in the slot region between the inner and the outer radiation belts is marked.

[40] The Cluster data show that these structures are formed in the same energy range for all the major ion species $\left(\mathrm{H}^{+}, \mathrm{He}^{+}\right.$and $\left.\mathrm{O}^{+}\right)$. This is a challenging result, since the trajectories that these ions follow when they are injected inward from their source in the near-tail plasma sheet are very different, because of the property of the magnetosphere to behave as a giant ion mass spectrometer [e.g., Balsiger et al., 1980; Fu et al., 2002], and the response of these ion populations to the energization mechanisms varies with their mass to charge ratio [e.g., Delcourt and Sauvaud, 1994]. Modeling efforts of nose-like structure formation, until now limited mainly to $\mathrm{H}^{+}$, should in the future be able to reproduce their multispecies character.

[41] The observation of the nose-like structures both inside and outside of the plasmasphere implies that erosion due to Coulomb interactions with the dense plasmaspheric population should not be an important loss mechanism for the energetic ions that form them.

[42] Following the onset of a magnetic storm these noselike structures, which require extended periods of relatively quiet magnetospheric conditions for their formation, are swept away by the more intense fluxes of the freshly injected ions. During these storm conditions the ring currentplasma sheet transition becomes more diffuse, and no clear boundary between these two populations can any more be identified.

[43] The $L$ shell extent in the dayside of the quiet time ring current ion populations, in the high latitudes explored by Cluster, can go out to $>10$, indicating that magnetopause shadowing is probably the delimiting factor for the drifting ions. In the nightside, however, these ring current ion populations are not observed beyond $L \approx 9$, the plasma sheet (or lobe at higher latitudes) taking over. Although at these high magnetic latitudes the physical meaning of the $L$ parameter is model dependent and thus less accurate, it still gives a reasonable estimate of the topology of the magnetic flux tube in which they are trapped.

\section{Conclusions}

[44] To summarize, the main conclusions that can be drawn from this study are the following: (1) The large-scale character of multiple nose-like structures, extending in latitude, MLT, and radial distance, covering also the outer radiation belt and sometimes the slot region, down to $L<2$. (2) The observation of the nose-like structures both inside and outside of the plasmasphere. (3) Their very complex energy spectrum, double and triple nose-like (or banded energy) structures being sometimes present. (4) These structures are 
formed in the same energy range for all the major ion species: $\mathrm{H}^{+}, \mathrm{He}^{+}$and $\mathrm{O}^{+}$. (5) Following the onset of a magnetic storm, the nose-like structures are swept away by the more intense fluxes of the freshly injected ions.

[45] These results pose a challenge for the simulation and modeling of the inner magnetosphere populations. Numerical particle trajectory simulation codes will have to reproduce the features reported here and explain their multiscale complexity, i.e., the large-scale spatial character of these multiple narrow energy bands, and their multi ion species character. Such simulations are very sensitive to the electric field model used [e.g., Ganushkina et al., 2005; Buzulukova and Vovchenko, 2008], which implies that the observations reported here will constitute a test ground for inner magnetosphere electric field models.

[46] The operation of the NUADU experiment [McKennaLawlor et al., 2005], which is an ENA imager onboard the Double Star TC-2 spacecraft, on a polar orbit, provides additional possibilities for analyzing the ring current ion populations: by simultaneous in situ measurements onboard Cluster and Double Star TC-1 and remote sensing measurements onboard Double Star TC-2. This is possible when Cluster and/or TC-1 are favorably positioned within the field-of-view of the ENA imager onboard TC-2, and the ring current activity is high enough to allow imaging of the ring current with adequate ENA counting statistics. Complete conjunctions in the inner magnetosphere, involving all the above spacecraft and occurring during high magnetospheric activity conditions, are rare.

[47] Acknowledgments. The authors are grateful to Natalia Ganushkina for helpful discussions. The Cluster and Double Star FGM data, used for the pitch angle calculations, were provided by the FGM team, Imperial College, London. The Cluster EFW data are supplied by the EFW team and the CAA (Cluster Active Archive). The Dst index was provided by the World Data Center for Geomagnetism, Kyoto. We acknowledge also the use of the ACE and GOES data. Jinbin Cao is supported by National Basic Research Program of China (2006CB806305).

[48] Zuyin Pu thanks Qiu Gang Zong and two other reviewers for their assistance in evaluating this manuscript.

\section{References}

Angelopoulos, V., M. Temerin, I. Roth, F. S. Mozer, D. Weimer, and M. R. Hairston (2002), Testing global storm-time electric field models using particle spectra on multiple spacecraft, J. Geophys. Res., 107(A8), 1194, doi:10.1029/2001JA900174.

Balogh, A., et al. (2001), The Cluster magnetic field investigation: Overview of in-flight performance and initial results, Ann. Geophys., 19, $1207-1217$

Balsiger, H., P. Eberhardt, J. Geiss, and D. T. Young (1980), Magnetic storm injection of 0.9 - to $16-\mathrm{keV} / \mathrm{e}$ solar and terrestrial ions into the highaltitude magnetosphere, J. Geophys. Res., 85, 1645-1662, doi:10.1029/ JA085iA04p01645.

Buzulukova, N. Y., and V. V. Vovchenko (2008), Modeling of proton nose structures in the inner magnetosphere with a self-consistent electric field model, J. Atmos. Sol. Terr. Phys., 70, 503-510, doi:10.1016/ j.jastp.2007.08.028.

Buzulukova, N. Y., R. A. Kovrazhkin, A. L. Glazunov, J. A. Sauvaud, N. Y Ganushkina, and T. I. Pulkkinen (2003), Stationary nose structure of protons in the inner magnetosphere: Observations by the ION Instrument onboard the Interball-2 Satellite and modeling, Cosmic Res., Engl. Transl., 41(1), 3-12, doi:10.1023/A:1022343327565.

Carr, C., et al. (2005), The Double Star magnetic field investigation: Instrument design, performance and highlights of the first year's observations, Ann. Geophys., 23, 2713-2732.

Daglis, I. A., R. M. Thorne, W. Baumjohann, and S. Orsini (1999), The terrestrial ring current: Origin, formation and decay, Rev. Geophys., 37, 407-438, doi:10.1029/1999RG900009.

Dandouras, I., et al. (2005), Multipoint observations of ionic structures in the plasmasphere by CLUSTER-CIS and comparisons with IMAGE-
EUV observations and with model simulations, in Inner Magnetosphere Interactions: New Perspectives From Imaging, Geophys. Monogr. Ser. edited by J. Burch, M. Schulz, and H. Spence, vol. 159, pp. 23-53, AGU, Washington, D. C.

Darrouzet, F., et al. (2004), Density structures inside the plasmasphere: Cluster observations, Ann. Geophys., 22, 2577-2585.

Delcourt, D. C., and J. A. Sauvaud (1994), Plasma sheet ion energization during dipolarization events, J. Geophys. Res., 99, 97-108, doi:10.1029/ 93JA01895.

De Michelis, P., I. A. Daglis, and G. Consolini (1997), Average terrestrial ring current derived from AMPTE/CCE-CHEM, J. Geophys. Res., 102, $14,103-14,111$

Dunlop, M. W., A. Balogh, K.-H. Glassmeier, and P. Robert (2002), Fourpoint Cluster application of magnetic field analysis tools: The Curlometer, J. Geophys. Res., 107(A11), 1384, doi:10.1029/2001JA005088.

Ebihara, Y., M. Ejiri, H. Nilsson, I. Sandahl, M. Grande, J. F. Fennell, J. L. Roeder, D. R. Weimer, and T. A. Fritz (2004), Multiple discrete-energy ion features in the inner magnetosphere: 9 February 1998 event, Ann. Geophys., 22, 1297-1304.

Ejiri, M. (1978), Trajectory traces of charged particles in the magnetosphere, J. Geophys. Res., 83, 4798-4810, doi:10.1029/JA083iA10p04798.

Ejiri, M., R. A. Hoffman, and P. H. Smith (1980), Energetic particle penetrations into the inner magnetosphere, J. Geophys. Res., 85, 653-663, doi:10.1029/JA085iA02p00653

Escoubet, C. P., M. Fehringer, and M. Goldstein (2001), The Cluster mission, Ann. Geophys., 19, 1197-1200.

Fu, S. Y., Q. G. Zong, T. A. Fritz, Z. Y. Pu, and B. Wilken (2002), Composition signatures in ion injections and its dependence on geomagnetic conditions, J. Geophys. Res., 107(A10), 1299, doi:10.1029/ 2001JA002006.

Ganushkina, N. Y., et al. (2000), Entry of plasma sheet particles into the inner magnetosphere as observed by Polar/CAMMICE, J. Geophys. Res., 105, 25,205-25,220, doi:10.1029/2000JA900062.

Ganushkina, N. Y., T. I. Pulkkinen, and T. Fritz (2005), Role of substormassociated impulsive electric fields in the ring current development during storms, Ann. Geophys., 23, 579-591.

Gustafsson, G., et al. (2001), First results of electric field and density observations by Cluster EFW based on initial months of operation, Ann. Geophys., 19, 1219-1240.

Huang, C. Y., W. J. Burke, and C. S. Lin (2005), Ion precipitation in the dawn sector during geomagnetic storms, J. Geophys. Res., 110, A11213, doi:10.1029/2005JA011116.

Jordanova, V. K. (2005), Sources, transport and losses of energetic particles during geomagnetic substorms, in The Inner Magnetosphere: Physics and Modeling, Geophys. Monogr. Ser, vol. 155, edited by T. I. Pulkkinen, N. A. Tsyganenko, and R. H. W. Friedel, pp. 9-22, AGU, Washington, D. C.

Keiling, A., et al. (2004), New properties of energy-dispersed ions in the plasma sheet boundary layer observed by Cluster, J. Geophys. Res., 109, A05215, doi:10.1029/2003JA010277.

Kovrazhkin, R., J.-A. Sauvaud, and D. Delcourt (1999), Interball-Auroral observations of the $0.1-12 \mathrm{keV}$ ion gaps in the diffuse auroral zone, Ann. Geophys., 17, 734-742.

Lennartsson, W., E. G. Shelley, R. D. Sharp, R. G. Johnson, and H. Balsiger (1979), Some initial ISEE-1 results on the ring current composition and dynamics during the magnetic storm of December 11, 1977, Geophys. Res. Lett., 6(6), 483-486, doi:10.1029/GL006i006p00483.

McIlwain, C. E. (1961), Coordinates for mapping the distribution of magnetically trapped particles, J. Geophys. Res., 66, 3681

McKenna-Lawlor, S., J. Balaz, S. Barabash, K. Johnsson, L. Zhenxing, L. Li, C. Jin-Bin, S. Chao, Q. Zong, E. C. Roelof, P. C. son Brandt, K. Kudela, $\mathrm{S}$. Fu, and I. Dandouras (2005), An overview of the scientific objectives and technical configuration of the NeUtral Atom Detector Unit NUADU for the Chinese Double Star Mission, Planet. Space Sci., 53, 335-348, doi:10.1016/j.pss.2004.09.060.

Pedersen, A., P. Décréau, C.-P. Escoubet, G. Gustafsson, H. Laakso, P.-A. Lindqvist, B. Lybekk, A. Masson, F. Mozer, and A. Vaivads (2001), Four-point high time resolution information on electron densities by the electric field experiments (EFW) on Cluster, Ann. Geophys., 19, $1483-1489$

Plainaki, C., H. Mavromichalaki, A. Belov, E. Eroshenko, and V. Yanke (2007), Application of the NM-BANGLE model to GLE70, paper presented at 30th International Cosmic Ray Conference, Univ. Nac. Auton. de México City, Merida, Mexico.

Rème, H., et al. (2001), First multispacecraft ion measurements in and near the Earth's magnetosphere with the identical CLUSTER Ion Spectrometry (CIS) Experiment, Ann. Geophys., 19, 1303-1354.

Rème, H., et al. (2005), The HIA instrument onboard the Tan Ce 1 Double Star near-Equatorial spacecraft and its first results, Ann. Geophys., 23 $2757-2774$ 
Robert, P., and A. Roux (1993), Dependence of the shape of the tetrahedron on the accuracy of the estimate of the current density, in Spatiotemporal Analysis for Resolving Plasma Turbulence (START), edited by European Space Agency, pp. 289-293, Eur. Space Agency, Paris.

Shirai, H., K. Maezawa, M. Fujimoto, T. Mukai, Y. Saito, and N. Kaya (1997), Monoenergetic ion drop-off in the inner magnetosphere, J. Geophys. Res., 102, 19,873-19,881, doi:10.1029/97JA01150.

Smith, P. H., and R. A. Hoffman (1974), Direct observations in the dusk hours of the characteristics of the storm time ring current particles during the beginning of magnetic storms, J. Geophys. Res., 79, 966-971, doi:10.1029/JA079i007p00966.

Tsyganenko, N. A. (1989), A magnetospheric magnetic field model with a warped tail plasma sheet, Planet. Space Sci., 37, 5-20, doi:10.1016/ 0032-0633(89)90066-4.

Vallat, C., et al. (2004), First comparisons of local ion measurements in the inner magnetosphere with ENA magnetospheric image inversions: ClusterCIS and IMAGE-HENA observations, J. Geophys. Res., 109, A04213, doi:10.1029/2003JA010224

Vallat, C., I. Dandouras, M. Dunlop, A. Balogh, E. Lucek, G. K. Parks, M. Wilber, E. C. Roelof, G. Chanteur, and H. Rème (2005), First current density measurements in the ring current region using simultaneous multispacecraft CLUSTER-FGM data, Ann. Geophys., 23, 1849-1865.
Vallat, C., N. Ganushkina, I. Dandouras, C. P. Escoubet, M. Taylor, H. Laakso, A. Masson, J.-A. Sauvaud, H. Rème, and P. Daly (2007), Ion multi-nose structures observed by Cluster in the inner magnetosphere, Ann. Geophys., 25, 171-190.

Williams, D. J. (1987), Ring current and radiations belts, Rev. Geophys., 25(3), 570-578, doi:10.1029/RG025i003p00570.

Yamauchi, M., et al. (2005), Structures of sub-keV ions inside the ring current region, in The Inner Magnetosphere: Physics and Modeling, Geophys. Monogr. Ser., vol. 155, edited by T. I. Pulkkinen, N. A. Tsyganenko, and R. H. W. Friedel, pp. 41-46, AGU, Washington, D. C.

Yamauchi, M., et al. (2006), Source location of the wedge-like dispersed ring current in the morning sector during a substorm, J. Geophys. Res., 111, A11S09, doi:10.1029/2006JA011621.

J. Cao, State Key Laboratory of Space Weather, CSSAR, CAS, P.O. Box 8701, Beijing 100080, China.

I. Dandouras, Centre d'Etude Spatiale des Rayonnements, Université de Toulouse, UMR5187, 9 Avenue du Colonel Roche, BP 44346, F-31028 Toulouse CEDEX 4, France. (iannis.dandouras@cesr.fr)

C. Vallat, VEGA, European Space Agency, Camino Bajo del Castillo s/n, Urbanizacion Villafranca del Castillo, P.O. Box - Apartado de Correos 78, E-28691 Madrid, Spain. 